keywords: radioactive contamination, radiation exposure, direct and mediated consequences, emergency costs, radiation exposure risk, collective dose, integral damage

\title{
ASSESSMENT OF POPULATION AND TERRITORY REHABILITATION EFFICIENCY REGARDING RADIATION EXPOSURE
}

The suggested assessment of rehabilitation measure efficiency is distinguished by the fact that integral risk interpretation is considered, which takes total radiation exposure and reduction of life standards caused by it into account. A rehabilitation measure structure in the context of radiation emergency is given. Classification of direct and mediated consequences of an emergency is given. Optimization of rehabilitation measures is carried out from the position of quality and security of life balancing. Corresponding expenses are compared to the cost of radiation exposure and its social equivalent damage. The role of an efficiency criterion is given to an integral damage minimum.

Negative consequences of anthropogenic influence on the environment on a global scale acquired a status of an extreme ecological problem. The real threat for future generations has appeared. The International Commission on environment and development suggested a conception of sustainable development, which implies balanced solutions for socioeconomic issues and keeping natural resources on the basis of the "golden triangle".

Ruinous anthropogenic influence on ecosystems requires economic analysis in terms of ecological security conditions and its optimization measures. Risk assessment is the basis for such an analysis.

The most important element of ecological security is radiation security. The term «radiation security» is defined as a state when present and future generations are protected from an ionizing radiation effect detrimental to health. According to the International commission on radiation security (ICRP) summary, in case if radiation protection of a human is provided, then other species are considered to be protected on a population level as well.

Nuclear fuel cycle enterprises are operating in our country, the nuclear power industry is developing, and by present $\sim 1,5 \cdot 10^{9} \mathrm{Ci}$ (Curie) of nuclear waste has been accumulated, aqueous medium contains $\sim 7 \cdot 10^{8} \mathrm{Ci}$ of it, including the waste that is connected straight with the hydrographic systems. $\sim 10^{8} \mathrm{~m}^{3}$ of spoil with the total activity $\sim 10^{5} \mathrm{Ci}$ are concentrated at mining and processing enterprises. The requirements for development of principles referred to radiation security of the population of our country have become particularly urgent after the Chernobyl NPP disaster [1] in 1986. Following it, the State programs for surmounting of the technological damage aftermaths at the «Lighthouse» production association in the Ural region (1949-1955, 1957, 1967) were adopted [9], as well as the consequences of the nuclear weapon tests on the Semipalatinsk testing area (1949-1953) for the population of the Altai region [4]. Radioactive contamination of natural entities and radiation damage of the population bear a long-term and in some cases irreversible nature.

In 90-s a fundamental legislative package concerned with handling of radioactive materials was adopted in the Russian Federation; it included the following laws: «About nuclear power utilization», «About radiation security of the population». Radiation security of the population exposed to accidental anthropogenic irradiation proceeds from territory zoning on the basis of risk intensity regarding residence $[10,11]$. Its assessment can be made efficiently according to the data of gammaairborne-mapping with subsequent State mapping according to long-living radionuclides, such as ${ }^{90} \mathrm{Sr}$, ${ }^{137} \mathrm{Cs} \mathrm{Pu}$ isotopes. In our country maximum intensity risk from ionizing radiation exposure is approved at a level $5 \cdot 10^{-5}$ year $^{-1}$ that is equivalent to the efficient dose of 1 microsievert per year $(\mu \mathrm{Sv} /$ year) or 7 centisievert for life [6].

Residence and economic activity on a territory with risk intensity in dose units $(D)$ up to $1 \mu \mathrm{Sv} /$ year is not limited. Dose assessment of critical groups of population is carried out in radiation control zones $((1 \div 5) \mathrm{mZv} / \mathrm{year})$, and measures referred to reduction of the given doses are being taken. Measures for vital activity restriction and nature management in particular are being taken in limited residence zones. Resettlement is provided in exclusion zones (over $20 \mu \mathrm{Sv} /$ year). Radioactive contamination of life environment and irradiation of the population specify the basic direct aftermaths of extreme radiation situations.

Subject to an absorbed dose value deterministic (individually causal) and stochastic (random) effects 
are distinguished. Deterministic effects are manifested at risk intensity il $\mathrm{Sv} /$ year. They appear in the form of radiation sickness, acute radiation reactions. Such effects developed for the remote population cohorts in the settlements of the coastal zone of the Techa river in the Ural region. At risk intensity $\sim 10 \mathrm{cSv} /$ year and less only stochastic effects appear: oncologic pathologies and genetic hereditary deflections. Stochastic effects are estimated by collective dose $\mathrm{R}$, man-Sv, by total efficient equivalent doses of the population cohort under consideration.

Regarding stochastic doses according to the nonthreshold linear concept [6]:

$$
R=\rho D,
$$

where $\rho$ is a risk factor. Risk is understood as individual probability of disease development (fatal outcome) subject to a specific factor. Total risk intensity $\dot{r}$ (its increment in unit time for the developed countries is estimated by the value $\sim 10^{-2}$ year $^{-1}$ (one case per 100 men per year). Risk of anthropogenic factor influence on life environment makes not less than $10 \%$ of the given value. Risk restriction is set by social-sanitary regulations. Its top limit admissible is correlated with the risk existing in the everyday life or production activity. With the age cohort weight taken into consideration, a risk factor in terms of oncological and genetic effects of radiation exposure amounts to $\rho \simeq 7,3 \cdot 10^{-2}$ manSv. It is a common practice to consider that risk due to a collective dose of $1 \mathrm{manSv}$ is equivalent to minus one year of the total life of the considered cohort. On the average, one oncological disease results in minus $(10 \div 15)$ years of living. As a result of the Chernobyl disaster the expected collective dose can amount to $\sim 10^{5}$ manSv. The consequences of the emergencies in the Ural region are estimated in more than $2 \cdot 10^{4}$ manSv. All the stated above affords an opportunity to characterize radioactive radiation influence on life environment in the region and a man himself (fig. 1) and to classify damage depending on ionizing radiation intensity (table).

Classification of damage caused by ionizing radiation demonstrates the fact that socioeconomic damage caused by radiation exposure is a complex record of ionizing radiation negative influence on a person, his life environment and an economic system. Reduction of such influence requires measures to be taken to prevent primary and remote consequences of radiation pollution elimination [3]. As also follows from the above said, there cannot be a general approach to assessment of total damage components; in this case a differentiated approach is required.

In reference to regions exposed to radiation, exposure rehabilitation policy proceeds from an economic analysis regarding security [12]. The purpose of the given policy is to compensate the population for harm to health and social welfare. Rehabilitation measure system lines include: radiation, medical, psychological, social-economic and legal security of the population exposed to anthropogenic emergency irradiation. On the basis of risk assessment security measures are taken, such as: voluntary resettlement, compulsory resettlement, radiation control and product quality inspection, deactivation of the polluted infrastructure objects and single territory zones, measures aimed at optimization of agricultural production system, ensuring labor conditions etc. [2].

The main issue concerned with security measure optimization is determination of risk cost a. This cost falls into a category of expenses, which cannot be unified. Its value depends considerably on a level of economic development of a territory exposed to ionizing radiation. A wide range of risk costs in different countries is indicative of that. Risk cost as an economic category is an extent of the risk effect on life quality. As any economic factor, it should meet two requirements:

- to have a straight or mediated influence on a man's life;

- to reflect possibilities to change such an influence.

From the considered points radiation safety is also a feature of personal life quality on a polluted territory, which assumes determination of threshold value a for a specific territory.

The risk cost should include two components:

$$
\alpha=\alpha_{x}+\alpha,
$$

where $\alpha_{x}-$ an economic component, it specifies straight damage from radiation exposure as a result of human loss as a producer of a product of public utility. $\alpha_{c}$-social component specifying compromise between personal attitude towards risk and demand by the society for an elevated risk activity. As a matter of fact, the given component reflects subjective estimation of life cost. According to the data of social monitoring among the population of a number of regions, its value averages to $\sim 3 \cdot 10^{5}$ rubles. As demonstrated by the rehabilitation practice regarding radiation polluted territories, social component ac considerably exceeds economic component $\alpha_{x}$. For our country threshold risk cost, offered by the ICRP (International Commission on Radiological Protection), is estimated as $\sim(10 \div 20)$ thousand dollars/cSv [7].

A set of measures aimed at radiation security establishment is associated with vital activity restrictions. Decline in a living standard occurs without an adequate social and economic support 


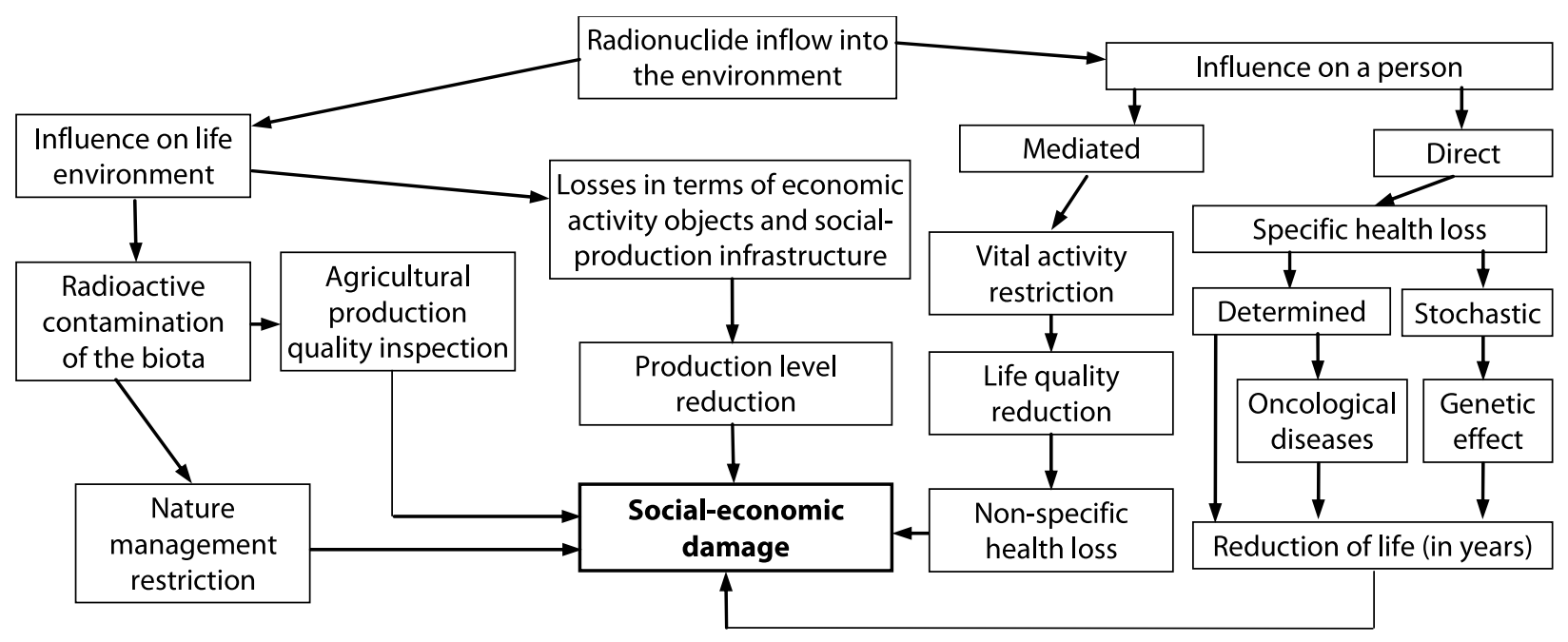

Fig. 1. Radioactive radiation influence on life environment pollution and a person

Table

Classification of damage caused by emergency radiation exposure

\begin{tabular}{|c|c|c|c|c|c|}
\hline $\begin{array}{c}\text { № } \\
\mathbf{b} / \mathbf{o}\end{array}$ & $\begin{array}{l}\text { Classification } \\
\text { criterion }\end{array}$ & $\begin{array}{l}\text { Recipient } \\
\text { exposure }\end{array}$ & Essential damage criterion & $\begin{array}{c}\text { Quantitative } \\
\text { (qualitative) values of } \\
\text { a criterion ( } \mathrm{mSv} / \text { year) }\end{array}$ & Damage types \\
\hline \multirow{4}{*}{1} & \multirow{4}{*}{$\begin{array}{l}\text { According to } \\
\text { ionizing radiation } \\
\text { intensity }\end{array}$} & $\begin{array}{l}\text { Admissible } \\
\text { exposure zone }\end{array}$ & \multirow{4}{*}{ Total radiation exposure } & $\mathrm{D}<1$ & Damage is not restricted \\
\hline & & $\begin{array}{l}\text { Radiation control } \\
\text { zone }\end{array}$ & & $\mathrm{D}=(1 \div 5)$ & $\begin{array}{l}\text { Damage in terms of } \\
\text { health loss risk by critical } \\
\text { groups of population }\end{array}$ \\
\hline & & $\begin{array}{l}\text { Restricted } \\
\text { residence zone }\end{array}$ & & $\mathrm{D}=(5 \div 20)$ & $\begin{array}{l}\text { Damage in terms of vital } \\
\text { activity restriction }\end{array}$ \\
\hline & & Exclusion zone & & $\mathrm{D}>20$ & $\begin{array}{l}\text { Damage in terms of vital } \\
\text { activity curtailment }\end{array}$ \\
\hline \multirow{2}{*}{2} & \multirow{2}{*}{$\begin{array}{l}\text { According to } \\
\text { ionizing radiation } \\
\text { manifestation }\end{array}$} & Person & $\begin{array}{l}\text { Radiation sickness, acute } \\
\text { radiation reaction }\end{array}$ & $\mathrm{D} \geq 1 \mathrm{Zv} /$ year & Determined damage \\
\hline & & Person & $\begin{array}{l}\text { Oncological pathology, } \\
\text { genetic hereditary deflections }\end{array}$ & $\mathrm{D} \leq 10 \mathrm{cZv} /$ year & Stochastic damage \\
\hline \multirow{4}{*}{3} & \multirow{4}{*}{$\begin{array}{l}\text { According to } \\
\text { ionizing radiation } \\
\text { coverage }\end{array}$} & \multirow{2}{*}{ Person } & Specific health loss & & Direct damage \\
\hline & & & Vital activity restriction & & Mediated damage \\
\hline & & Life environment & $\begin{array}{l}\text { Radioactive biota } \\
\text { contamination }\end{array}$ & & $\begin{array}{l}\text { Nature management } \\
\text { restriction, agricultural } \\
\text { production brokerage } \\
\end{array}$ \\
\hline & & $\begin{array}{l}\text { Economic } \\
\text { systems }\end{array}$ & $\begin{array}{l}\text { Losses of economic activity } \\
\text { objects and social-production } \\
\text { infrastructure }\end{array}$ & & $\begin{array}{l}\text { Damage in terms of } \\
\text { production volume loss }\end{array}$ \\
\hline \multirow[b]{2}{*}{4} & \multirow{2}{*}{$\begin{array}{l}\text { According to } \\
\text { remoteness } \\
\text { of ionizing } \\
\text { radiation effect } \\
\text { manifestation }\end{array}$} & \multirow[b]{2}{*}{$\begin{array}{l}\text { Population, } \\
\text { territory }\end{array}$} & Security of the population & & Primary damage \\
\hline & & & $\begin{array}{l}\text { Generation of conditions for } \\
\text { long-term residence of the } \\
\text { population on a radioactively } \\
\text { polluted territory }\end{array}$ & & $\begin{array}{l}\text { Predictable damage } \\
\text { (secondary) }\end{array}$ \\
\hline
\end{tabular}

of the population. Thereby, radiation emergency effects are subdivided into two groups:

- direct, subject to radiation exposure;

- mediated, connected with vital activity restrictions.

In the aggregate, a cost equivalent of the specified effects determines primary and predictable damage.
Assessment of actual damage is principal in terms of rehabilitation policy substantiation. Primarily, the concept ALARA was declared as the principle for radiation protection; it implies employment of virtually all the feasible measures referred to danger elimination. Along with that, a nonthreshold concept allows to consider radiation exposure 


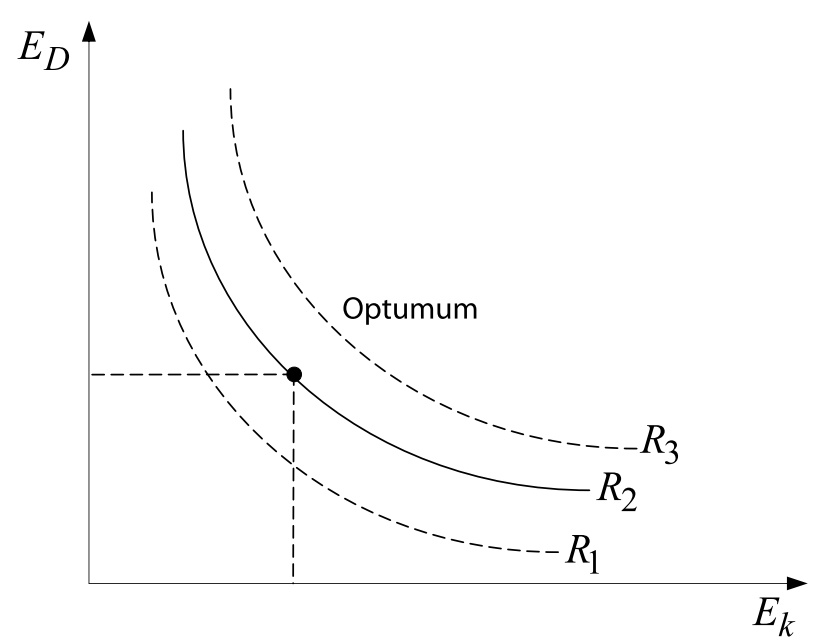

Fig. 2. Constant risk value in coordinate system related to costs: "security - life quality" ( $E_{D}$ - efficiency of primary costs, $E_{k}-$ efficiency of secondary costs)

standards in the context of different situations, based on taking the correlation «harm - benefit» into consideration. In the context of comparison of harm and benefit, an optimum distribution in terms of time of expenses $3_{\Sigma}$ for security and life quality on the given territories is to take into account its functional dependence on the existing economic opportunities (fig. 1). Each line related to the overall risk $R=$ const on fig. 2 correlates with distinguishing economic resources. Depending on a volume of rehabilitation costs $\left(3_{5}\right)$ and segmentation of the given costs into two utilization lines (security and quality of life), an optimum of rehabilitation measures under predictable tolerable risk will be determined by a minimum of total cost $[2,3]$ :

$$
3_{\Sigma}=3_{D}+3_{K} \text {, }
$$

where $3_{D}-$ costs of reduction of the total radiation burden on the territory, $3_{K}-$ costs of life quality optimization.

In large-scale emergencies there is no possibility to take simultaneous and comprehensive rehabilitation measures due to limited financial and material resources. In order to find a proportion optimum taking the set goals into consideration, it is reasonable to determine efficiency rates referred to primary $\left(E_{D}\right)$ and secondary $\left(E_{k}\right)$ costs. Objectives that need to be accomplished under radiation emergencies are subdivided into two groups:

1. Primary rehabilitation of a territory, population, aimed at attaining admissible radiation dose with the minimum financial resources available;

2. Remote rehabilitation, intended for assurance of security and life quality for the population in the future (resettlement, rehabilitation measures etc.).

Minimum $Z$ factor (integral damage) including sustained loss compensation costs and remanent damage $Y_{\text {rem }}$ after taking rehabilitation measures can serve as a criterion of rehabilitation measure efficiency:

$$
Z=3_{S}+Y_{\text {rem }} \rightarrow \min ,
$$

$Z$ factor includes costs of the incurred damage compensation.

Protective measure costs (fig. 3) aimed at radiation dose reduction regarding the population exposed to radiation, determine cost $3_{D}$ of the precluded dose $D$ :

$$
3=3_{D}=\beta D .
$$

Efficiency $E_{D}$ of primary measures intended for radiation dose reduction, is estimated by comparison of costs $\left(3_{D}\right)$ to the precluded collective dose cost (operation dose cost $\alpha D_{0}$ ):

$$
E_{D}=\frac{\alpha D_{0}}{3_{i}} .
$$

However, it is essential to understand that large-scale rehabilitation of territories and water objects is unrealizable in case of their radioactive contamination. It is possible to consider the required cost comparison to the cost equivalent estimating the life environment [5], including a cadastre cost. In practice, rehabilitation measures relative to natural environment are reduced to nature management restriction up to sanitary protection zone arrangement.

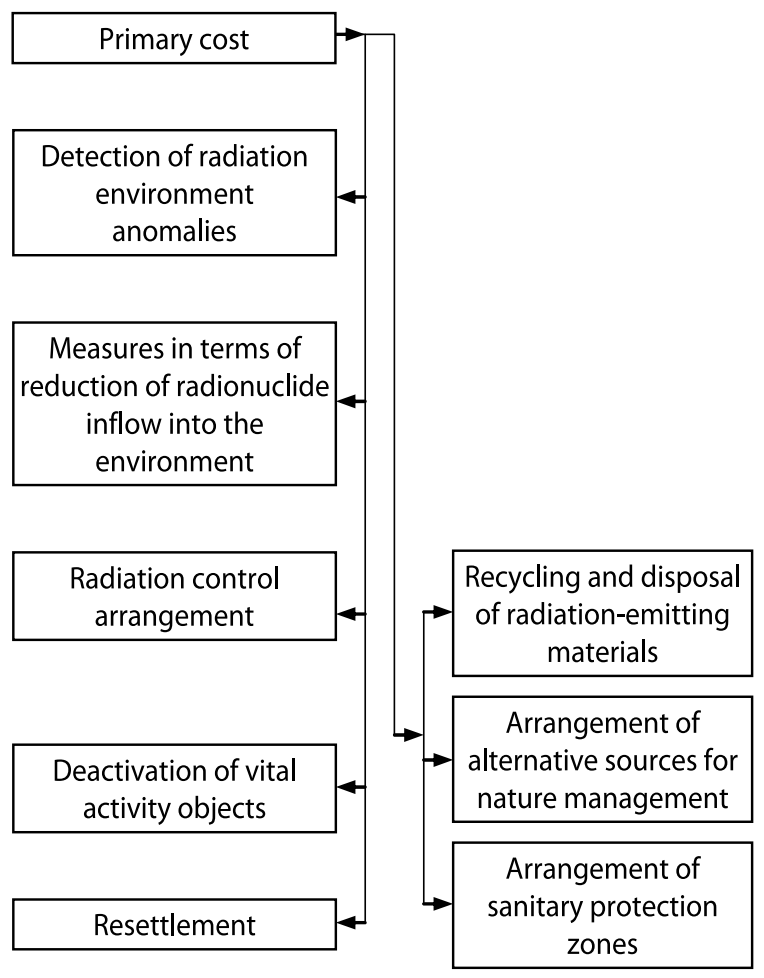

Fig. 3. Structure of costs of primary rehabilitation of a territory exposed to radiation 


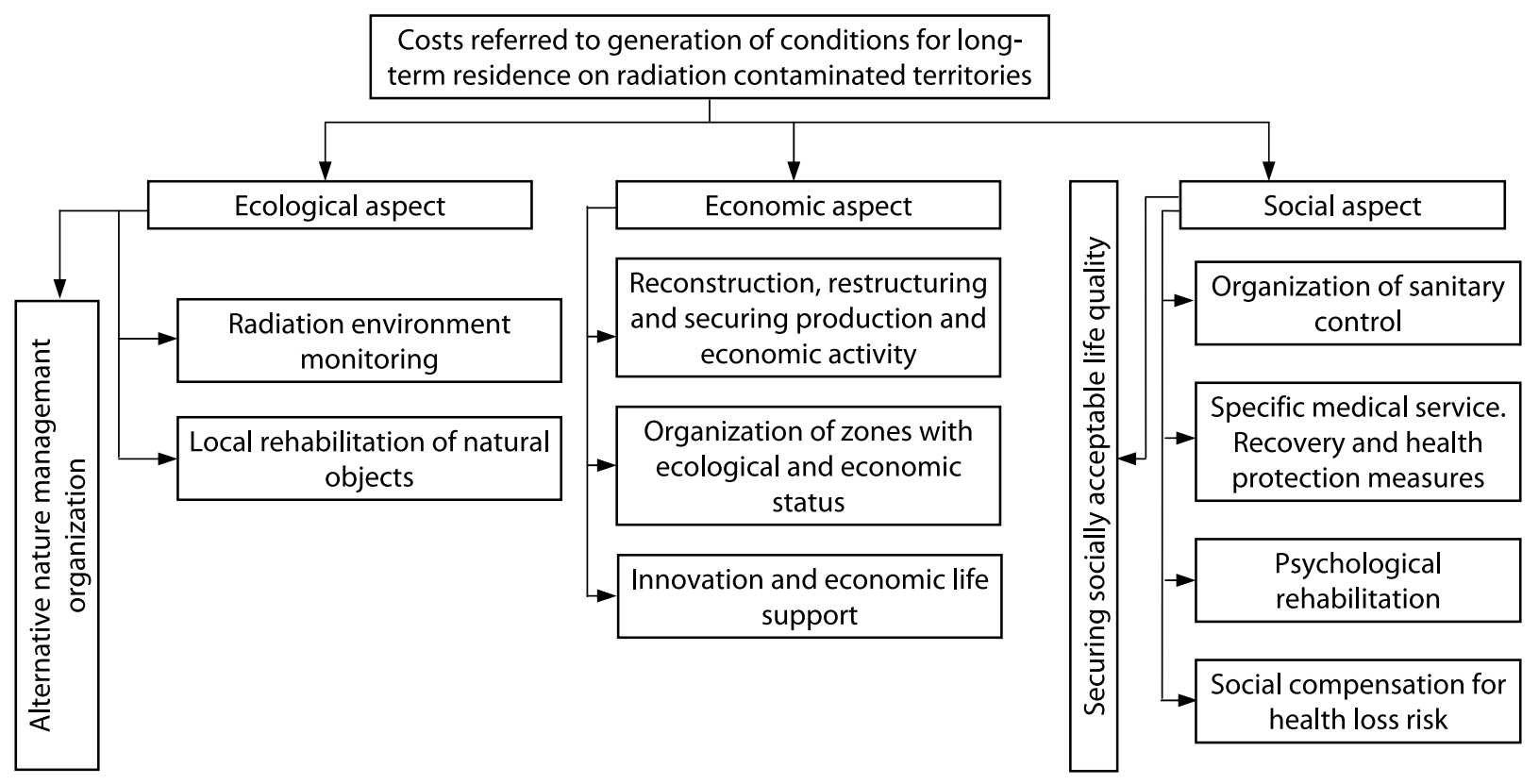

Fig. 4. Structure of costs referred to generation of conditions for long-term residence on radiation contaminated territories

As the problem of radiation security is being solved, high priority is given to generation of conditions (taking measures) for long-term residence on radiation contaminated territories, with a level and quality of life being taken into account as well (fig. 4).

In the course of examination of remote aftermaths it is reasonable to take into account a social equivalent of the accumulated dose, which, as opposed to radiation exposure effects, results in nonspecific health loss. Increase in annual income by $1 \%$ corresponds to reduction of risk by $\sim 5 \cdot 10^{-5}$ year $^{-1}$ that is equivalent to precluded dose $1 \mathrm{mSv} \cdot \mathrm{year}^{-1}$ [8]. Efficiency of investments aimed at life quality optimization, is determined by the criterion:

$$
E_{k}=\frac{k}{k_{0}},
$$

where $k_{0}$ and $k$ - life quality in value terms on the basis of comparable factor sum-total before and after the rehabilitation measures.

Consequences of life environment radioactive contamination are characterized by time dilatation in reference to receding radiation risk, which can remain significant for decades and even centuries. It is obvious that a unified system of rehabilitation measures in the context of such periods is pointless to be created. On the other hand, the problem occurs as to an alternative regarding single-step or gradual investments into security and quality of life. The first option assumes «freezing» of funds. To reach the specified security level with gradual investments, less funds and protective measures according to time spans are required.
Dilatation of rehabilitation measures in time is based on discounting of damage:

$$
Y(0)=\int_{0}^{\infty} \dot{Y}(t) e^{m t} d t
$$

where $p$ - rate of discounting. Determination of a numerical value related to the discounting rate is a multiple-factor problem. Economic approach to damage evaluation subject to radiation exposure assumes collective dose discounting:

$$
D(0)=\int_{0}^{\Sigma} \dot{D}(t) e^{p t} d t
$$

Integrating limit $\tau$ is determined with a glance to an initial dose rate $\dot{D}(0)$ and physical half-life of dose-generating radionuclides. Therewith, the discounting procedure should take standard dose framework into account.

The suggested technology related to assessment of social-economic damage caused by large-scale radiation emergencies is aimed, in our opinion, to enhancement of economic relevance regarding the system of rehabilitation measures implemented through goal-oriented programs.

\section{References}

1. Voznyak V. Y. Chernobyl. Return to life. Rehabilitation of radioactive polluted territories. M: Moscomplex, 1993. 208 p.

2. Volobuev P. V., Kozlova N. I. The Structure of direct and mediated consequences under radiation emergency. USTUUPI Bulletin. "Economic management” №1 (72). Ekaterinburg p. 39-50.

3. Kozlova N. I. Economic assessment of radiation emergency damage. Kurgan, KSU, 2008. 240 p. 
4. Logachev V. A. Semipalatinsk testing area. General and radiation security of nuclear tests M.: IGEM RAS, 1997. 342 p.

5. Methodological recommendations for selection of investment nature conservation projects for economic programs of the constituent entity of the Russian Federation / Chenenova R. I., Khilchenko N. V., Gavrikova N. V. etc. Ekaterinburg, Institute of economics UB RAS, 2004, 80 p.

6. Radiation security standards (RSS-99) M.: Ministry of Public health of the RF, 1999, $128 \mathrm{p}$.

7. Optimization of radiation protection on the basis of the correlation analysis «costs - benefit». Publication №37 ICRP. M.: Energoatomizdat, 1985. 96 p.

8. Pavlov I. V. Concept of radiation security of personnel and population at radioactive ore mining and processing enterprises. Funds by the All-Russian research and design institute for industrial technology. A-364-92, 1992. 20 p.

9. Anthropogenic radiation exposure aftermaths and rehabilitation issues in the Ural region // ed. By Shoygu S.S. M.: Komtechprint, 2002. 288 p.

10. Ramzaev P. V., Tsyb A. F. Concept for protection of population and economic activity on territories exposed to radioactive contamination. M.: PHKP, 1993. 8 p.

11. Tsyb A. F. Concept for radiation, medical, social security and rehabilitation of the population of the Russian Federation exposed to emergency irradiation. M.: PHK P3, 1993. 12 p.

12. Shevelev $Y$. V., Klimenko A. V. Efficient economy for a nuclear fuel-energy complex. M: Energy, 1996. 734 p. 